\title{
Antioxidants and their implication in oral health and general health
}

\author{
Lingam Amara Swapna, Koppolu Pradeep, Padma Reddy, \\ Koppolu Deepak, Stuti Goyal
}

\begin{abstract}
Introduction: Oxygen is extremely crucial for the existence of higher organisms. As the saying goes too much of even the best is awful. High and soaring concentration of oxygen are found to be toxic, and can damage tissues. Free radicals can adversely alter lipids, proteins and DNA and have been implicated in aging and in number of human diseases. Lipids are highly prone to free radical damage resulting in lipid peroxidation that can lead to adverse alterations. Free radical damage to protein can result in loss of enzyme activity. Damage caused to DNA, can result in mutagenesis and carcinogenesis. Nature has endowed us with protective antioxidant mechanisms from many dietary components. Thus, a greater consumption of fruits and vegetables should be encouraged as they are the natural sources of these chemopreventive antioxidants with other protective factors.
\end{abstract}

Lingam Amara Swapna ${ }^{1}$, Koppolu Pradeep ${ }^{2}$, Padma Reddy ${ }^{3}$, Koppolu Deepak ${ }^{4}$, Stuti Goyal ${ }^{5}$

Affiliations: ${ }^{1}$ Senior lecturer, Dept of Oral Medicine and Radiology, Sri Sai College of Dental Surgery, Vikarabad; ${ }^{2}$ Senior Lecturer, Dept of Periodontology, Sri Sai College of Dental Surgery, Vikarabad; ${ }^{3}$ Reader, Dept of community and preventive dentistry, Panineeya Institute of Dental Sciences, Hyderabad; "Senior Clinical Research Associate, George Institute, Hyderabad; ${ }^{5}$ Senior lecturer, Dept of Oral Medicine and Radiology, Sri Sai College of Dental Surgery, Vikarabad. Corresponding Author: Dr. Lingam Amara Swapna, Senior lecturer, Dept of Oral Medicine and Radiology, Sri Sai College of Dental Surgery, Vikarabad, A.P; Email: laswapna123@ ymail.com

Received: 04 July 2013

Accepted: 25 July 2013

Published: 01 April 2014
Keywords: Antioxidants, Beta carotene ( $\beta-$ carotene), Free radicals, 1,25-Dihydroxyvitamin D3 (1,25-D3).

\section{How to cite this article}

Swapna LA, Pradeep K, Reddy P, Deepak K, Goyal S. Antioxidants and their implication in oral health and general health. International Journal of Case Reports and Images 2014;5(4):258-263.

doi:10.5348/ijcri-201455-RA-10010

\section{INTRODUCTION}

In recent years there is an upsurge in the areas related to newer developments in prevention of disease especially the role of free radicals and antioxidants. This review compiles the pertinent possible role of 'free radicals' in disease and 'antioxidants' in its prevention, especially the current status of the antioxidants in oral diseases and future prospects and their application in dentistry. Antioxidants are compounds used by aerobic organisms for protection against oxidative stress, induced by free radicals and active oxygen species. They exert their protective action either by suppressing the formation of free radicals or by scavenging free radicals $[1,2]$. A wide range of biological effects, established experimentally, may inhibit carcinogenesis. These include effects on tumor initiation, promotion and progression, cell proliferation and differentiation, as well as DNA repair, cell membrane stability and immune function [3, 4]. Dietary antioxidants such as carotenoids, vitamins $\mathrm{C}$ and $\mathrm{E}$ and selenium have received much attention as potential cancer chemopreventive agents.

\section{Types of free radicals}

Oxygen is required in many metabolic reactions, particularly for the release of energy. During these 
processes, molecular oxygen is completely reduced and converted to water. However, if the reduction of oxygen is incomplete, a series of reactive radicals are formed [5-7].

Reactive oxygen species play an important role in cell signaling and metabolic processes, but also contribute to pathogenic processes in a variety of inflammatory disorders [7-11].

Healthy individuals maintain a balance between the reactive oxygen species and antioxidants.

\section{Harmful effects of free radicals}

Free radicals are highly reactive and are capable of damaging almost all types of biomolecules [2, 4]. The fact is that free radicals beget free radicals, i.e., generate free radicals from normal compounds which continue as a chain reaction.

\section{Free radicals and diseases}

Free radicals have been implicated in the causation and progression of several diseases such as

- Cardiovascular disease

- Cancer

- Inflammatory diseases

- Respiratory diseases

- Diabetes

- Cataract formation

- Male infertility

- Aging process

- Other diseases: Parkinson's disease, Alzheimer's disease, multiple sclerosis, liver cirrhosis, muscular dystrophy, toxemia of pregnancy, etc.

Antioxidants according to their location:

The following are some antioxidants according to their location $[1,5]$ :

(i) Plasma antioxidants: $\beta$-carotene, ascorbic acid, bilirubin, uric acid, ceruloplasmin, transferring.

(ii) Cell membrane antioxidants: $\alpha$-tocopherol.

(iii) Intra-cellular antioxidants: superoxide dismutase, catalase, glutathione peroxidase.

\section{ANTIOXIDANTS ROLE IN THE PREVENTION OF CANCER}

Antioxidants are considered as the scavengers of free radicals. DNA damage is the main culprit in the development of cancer. Greater extent of this damage is because of oxidative stress. Antioxidants are proved to cause the regression of premalignant lesions and also inhibit their development into cancer $[12,13]$ In general, high intake of fruits and vegetables are associated with a protective effect against cancer (Figure 1 and 2) [14, 15].

\section{LYCOPENE}

Lycopene is an important antioxidant abundant in tomatoes. Lycopene has been hypothesized to

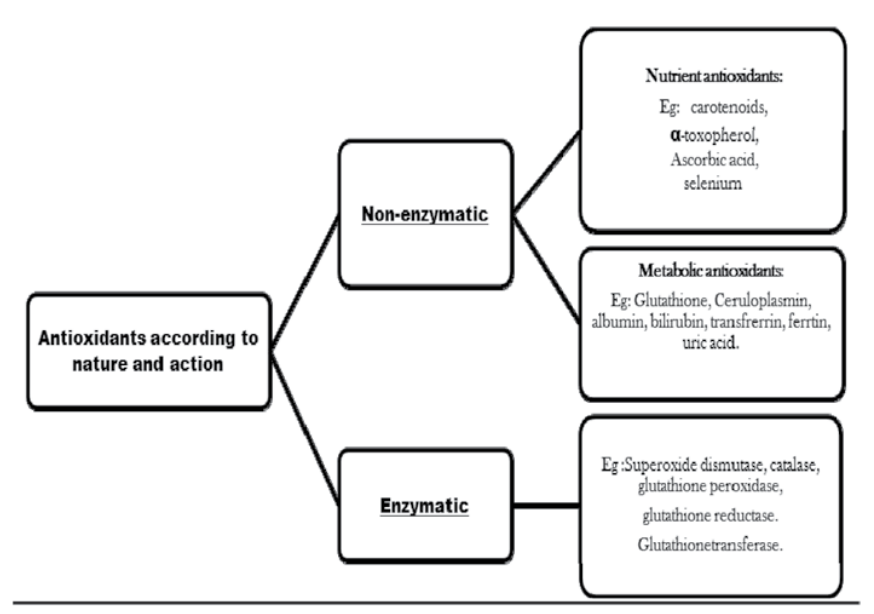

Figure 1: Type of Antioxidants.

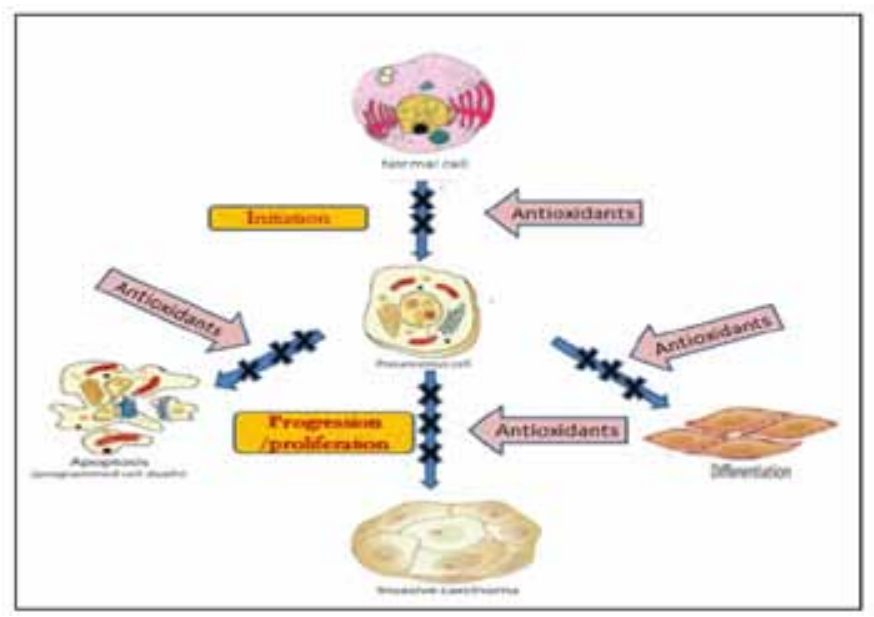

Figure 2: Proposed mechanism through which the antioxidants act. The Xs indicate the agent is hypothesized to inhibit carcinogenesis either by blocking initiation, progression/ proliferation or angiogenesis.

prevent carcinogenesis by protecting critical cellular biomolecules, including lipids, lipoproteins, proteins, and DNA. According to various studies, lycopene, when given in the dosage of $4.8 \mathrm{mg} /$ day orally for three months, leads to the reversal of dysplastic changes in leukoplakia and when given in the dosage of $16 \mathrm{mg} /$ day leads to substantial increase in the mouth opening in oral submucous fibrosis. On average, the daily permissible intake of lycopene is estimated to be $3.7 \mathrm{mg}[16,18]$.

Carotenoids: These are found in enormous quantities in green and yellow leafy vegetables. In addition, they have many other beneficial properties [19]. Furthermore, these compounds are comparatively nontoxic. Observational studies have indicated a protective effect of carotene rich vegetables, $\beta$-carotene, and carotenoids, on cancers of the oesophagus, colorectum, stomach, cervix, oropharynx, 
lung, and prostate [20-23].

Beta-carotene: A precursor of vitamin A has antioxidant and free radical scavenging property. It also helps in immunomodulation, promotes increase in the numbers of T-helper and NK cells as well as cells with IL-2 receptors and inhibits mutagenesis and cancer cell growth [13, 19-23].

Vitamin C: This is a water-soluble vitamin, an important free radical scavenger in plasma and acts to reinforce active vitamin $\mathrm{E}$ in lipid membranes. Vegetables, citrus fruits and tubers are good sources of vitamin $C$ [24]. The confirmation for a protecting effect of vitamin $\mathrm{C}$ is stronger for cancer of the stomach, and upper aerodigestive tract and weaker for other types of cancer [22-23]. It reduces vitamin $\mathrm{E}$ degradation, enhances chemotaxis, phagocytosis, collagen synthesis, inhibits nitrosamine formation, enhances detoxification via cytochrome P450. Blocks formation of mutagens and reduces expression of oncogenes.

Vitamin E: The most biologically active form of vitamin $\mathrm{E}$ is $\alpha$-tocopherol. It is fat-soluble vitamin, major lipid-soluble antioxidant of the cell membrane. It acts as a free-radical scavenger and inhibits peroxidation [25]. It has been reported to block the in vivo development of N-nitroso compounds [26]. Vegetable oils, wholewheat products and nuts are amongst the best sources of vitamin E. Overall, observational epidemiological studies suggest a protective effect of vitamin $\mathrm{E}$ against cancers of the lung, colorectum and the cervix [27, 28]. It is a free radical scavenging antioxidant, maintains membrane integrity, immune function and reduce cancer cell growth/differentiation, cell cytotoxicity, inhibits mutagenicity and nitrosamine formation, preservation of DNA and RNA including protein synthesis in cancer cells [29].

Selenium: This is a trace element and a critical cofactor for the major antioxidant enzyme glutathione peroxidase, which catalyses the oxidation of hydroperoxide [30]. Selenium is also implicated in cell signaling and immune reactions, which may furnish to its cancer chemopreventive potential [31]. Selenium and vitamin E may mutually compensate deficiency of each other and act synergistically to slow down carcinogenesis. The amount of selenium that is in our food is estimated by the selenium content of the soil in which fruits and vegetables are grown. Seafood, liver and meat are also good sources of selenium [32].

Flavonoids: These are phenolic compounds with anticarcinogenic properties. Tea polyphenols, in particular, are strong scavengers of superoxide, hydrogen peroxide, hydroxyl radicals and nitrogen oxides and may enhance the levels of antioxidant enzymes such as catalase. Flavonoids are abundantly available in fruits, vegetables and tea leaves. A number of animal studies have confirmed that catechins, the main flavonoids found in tea leaves, prevent induction of cancers of lungs, colon, esophagus, pancreas, and liver [33, 34].
Isoflavones: These are found chiefly in soy products. Isoflavones are structural isomers of flavonoids and allocate biological properties with them. They have antiestrogenic effects, and thus could act as chemopreventive agents in hormone dependent cancers. Genistein is a prominent isoflavone in soy foodstuffs known to promote apoptosis in vivo [35]. Epidemiologic studies advocate that population in Asian countries consuming high amounts of soy products may be at lower risk for prostate cancer and breast cancer [36].

Curcumin: This is a plant phenol widely used as a spice (curry) and food-coloring agent. In vivo and in vitro studies have demonstrated that it may prevent initiation of DNA damage and is involved in anti-promotion mechanisms such as apoptosis [37]. A number of animal studies have shown that curcumin is effective in inhibiting carcinogenesis in the skin, colon, stomach mammary gland and oral cavity [38].

\section{Other diet-derived agents}

Retinoids: The best known retinoid is vitamin A or retinol, found in foods of animal origin, such as liver, milk and dairy products, egg yolk and fish liver oils, they are required for the maintenance of normal cell growth and differentiation. In contrast to carotenoids, they act primarily in the post initiation phases of promotion and progression in carcinogenesis [39, 40].

Animal studies have shown that retinoids are potent to suppress or reverse epithelial carcinogenesis at several sites. The most promising results have been reported for oral carcinogenesis [41].

Vitamin D: 1,25-dihydroxyvitamin D3 (1,25-D3) is the active form of the fat-soluble vitamin D. Major dietary sources of vitamin D include liver, fatty saltwater fish and eggs. Vitamin D inhibits proliferation and DNA synthesis, alters expression of several oncogenes, reduces lipid peroxidation and angiogenesis and induces differentiation [42]. Epidemiologic studies support an inverse association among vitamin $\mathrm{D}$ intake and colorectal cancer risk [43].

Folic acid: It is majorly found in fresh fruits and vegetables. Together with vitamin B12, methionine and choline, it is involved in methyl group metabolism. Much of the basic cancer research has focused on DNA methylation, and hypomethylation has been associated with DNA abnormalities [44] A converse association involving dietary folate intake and adenomatous polyps or colorectal cancer has been stated in both case-control and cohort studies [45].

\section{THERAPEUTIC USE OF ANTIOXI- DANTS FOR ORAL LESIONS}
1. Prevention of lesions in high-risk individuals.
2. The treatment of premalignant oral lesions.
3. In order to prevent recurrence of the treated 
initial lesion or to prevent the development of a second or a separate primary.

Different antioxidants show significantly different levels of effectiveness in different fats, oils, and food materials due to their different molecular structures.

\section{Limitations of antioxidants}

Antioxidant therapy in human reproductive medicine is still a controversy [17]. High doses of vitamin A showed to have embryotoxic and teratogenic effects. Large doses of vitamin C (ascorbic acid) may be associated with the inhibition of ovarian steroidogenesis and increased probability of abortion [18]. Antioxidants supplements were once thought to be harmless but increasingly we are becoming aware of their interactions and potential toxicity. Also, very little is known about the long-term consequences of megadoses of antioxidants.

\section{CONCLUSION}

Dietary antioxidants protect us from the harmful affects of free radicals. Considerable evidence indicates that foods with high antioxidants nutrients play a major role in disease prevention. Efforts should be made to make these important molecules as our daily health regimen.

Finally, it can be said that

"Vegetables like carrot, tomato might someday keep the doctor away!!

Eat "fresh red fruits and vegetables" every day...

Consume them in right amounts for a healthy and long life...”.

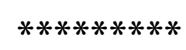

\section{Acknowledgements}

I would like to earnestly thank my guide Prof. Dr. R. Sudhakara reddy, Vishnu Dental College, and my heartfelt gratitude to my dear parents.

\section{Author Contributions}

Lingam Amara Swapna - Substantial contributions to conception and design, Acquisition of data. Drafting the article, Revising it critically for important intellectual content, Final approval of the version to be published Koppolu Pradeep - Substantial contributions to conception and design, Acquisition of data, Revising it critically for important intellectual content, Final approval of the version to be published

Padma Reddy - Substantial contributions to conception and design, Acquisition of data, Revising it critically for important intellectual content, Final approval of the version to be published

Koppolu Deepak - Substantial contributions to conception and design, Acquisition of data, Revising it critically for important intellectual content, Final approval of the version to be published
Stuti Goyal - Substantial contributions to conception and design, Acquisition of data, Revising it critically for important intellectual content, Final approval of the version to be published

\section{Guarantor}

The corresponding author is the guarantor of submission.

\section{Conflict of Interest}

Authors declare no conflict of interest.

\section{Copyright}

(C) Lingam Amara Swapna et al. 2014; This article is distributed under the terms of Creative Commons attribution 3.0 License which permits unrestricted use, distribution and reproduction in any means provided the original authors and original publisher are properly credited. (Please see www.ijcasereportsandimages.com/ copyright-policy.php for more information.)

\section{REFERENCES}

1. U. Satyanarayana, U. Chakrapani, 3rd edition. Books and allied (P) ltd, kolkata, 1999, pp 655-661

2. Papas A. Antioxidant Status, Diet, Nutrition and Health. Boca Raton, FL: CRC Press, 1999.

3. Radler D. R. "Nutritional supplements, ergogenic aids, and herbals, Dent Clin N Am 47 (2003) 245258.

4. Devasagayam TPA, Tilak JC, Boloor KK, Sane KS, Ghaskadbi SS, Lele RD. Free radicals and antioxidants in human health: current status and future prospects. JAPI 2004; 52: 794-804.

5. Schifferle R. E. Nutrition and Periodontal DiseaseDent Clin N Am 49 (2005) 595-610.

6. Clinical and laboratory assessment of nutrition status in dental practice. Dent Clin N Am 47 (2003) 259278.

7. Bloomer RJ. Decreased blood antioxidant capacity and increased lipid peroxidation in young cigarette smokers compared to nonsmokers: impact of dietary intake. J Nutr 2007; 6: 39-42.

8. Rao V. Bioavailability and in vivo antioxidant properties of lycopene from tomato products and their possible role in the prevention of cancer. Nutr Cancer 1998;31:199-203.

9. Prasad KN, Kumar A. High doses of multiple antioxidant vitamins: Essential ingredients in improving the efficacy of standard cancer therapy. J Am Coll Nutr 1999;18: 13-25.

10. Singh, Gaby. Premalignant lesions: Role of antioxidant vitamins and beta carotene in the risk reduction and prevention of malignant transformation. Am J Clin Nutr 1991; 53:386S-9oS.

11. Kaugars, Silverman, Lovas. A clinical trial of antioxidant supplements in the treatment of oral leukoplakia. Oral Surg Oral Med Oral Path1994;78:462-8.

12. Carnelio S, Khan SA. Free radicals and antioxidant therapy in clinical practice: To be or not to be. J Coll Physicians Surg Pak 2007;17: 173-4. 
13. Tamimi R. M, Lagiou P., Adami H.O. \& Trichopoulos D. Prospects for chemoprevention of cancer. Journal of Internal Medicine 2002; 251: 286-300.

14. Shetti A, Keluskar V, Aggarwal A. Antioxidants: Enhancing oral and general health Journal of Indian Academy of Oral Medicine and Radiology / Jan-Mar 2009 / Volume 21 / Issue 1;1-6

15. Meyers DG, Maloley PA, Weeks D. Safety of antioxidant vitamins. Arch Intern Med 1996;156:92535 .

16. Rao LG, Guns E, Venketrao A. Lycopene: Its role in human health and disease. Agro Food Industry 2003;25:1-6.

17. Kumar A, Bagewadi A, Keluskar V. Efficacy of lycopene in the management of oral submucous fibrosis. Oral Surg Oral Med Oral Path Oral Radiat Endod 2007;103:207-13.

18. Singh M, Krishanappa R, Bagewadi A, Keluskar V. Efficacy of oral lycopene in the treatmentof oral leukoplakia. Oral Oncol 2004;40:591-6.

19. Van Poppel G, Goldbohm RA. Epidemiologic evidence for beta-carotene and cancer prevention. Am J Clin Nutr 1995;62 (Suppl.): 1393S-1402S.

20. Willett WC. Vitamin A and lung cancer. Nutr Rev 1990; 48: 201-11.

21. Steinmetz KA, Potter JD. Vegetables, fruit, and cancer. I. Epidemiology. Cancer Causes Control 1991; 2: 325-57.

22. Ziegler RG, Mayne ST, Swanson CA. Nutrition and lung cancer. Cancer Causes Control 1996; 7: 157-77.

23. Stich HF, Rosin MP, Hornby AP, Mathew B, Sankaranarayanan R, Nair MK. Remission of oral leukoplakias and micronuclei in tobacco/betel quid chewers treated with betacarotene and with betacarotene plus vitamin A. Int J Cancer 1988; 42: 1959.

24. Block G. Epidemiologic evidence regarding vitamin C and cancer. Am J Clin Nutr 1991; 54: 1310S-1314S.

25. Burton GW, Cheeseman KH, Doba T, Ingold KU, Slater TF. Vitamin $\mathrm{E}$ as an antioxidant in vitro and in vivo. Ciba Found Symp 1983; 101: 4-18.

26. Mirvish SS. Effects of vitamins $\mathrm{C}$ and $\mathrm{E}$ on $\mathrm{N}$-nitroso compound formation, carcinogenesis, and cancer. Cancer 1986; 58 (Suppl.): 1842-50.

27. Comstock GW, Bush TL, Helzlsouer K. Serum retinol, betacarotene, vitamin $\mathrm{E}$, and selenium as related to subsequent cancer of specific sites. Am J Epidemiol 1992; 135: 115-21.

28. Longnecker MP, Martin-Moreno JM, Knekt P et al. Serum alpha-tocopherol concentration in relation to subsequent colorectal cancer: pooled data from five cohorts. J Natl Cancer Inst 1992; 84: 430-5.

29. The ATBC Cancer Prevention Study Group. The effect of vitamin $\mathrm{E}$ and beta-carotene on the incidence of lung cancer and other cancers in male smokers. N Engl J Med 1994; 330: 1029-35.

30. Hoekstra WG. Biochemical function of selenium and its relation to vitamin E. Fed Proc 1975; 34: 2083-9.

31. Medina D. Mechanisms of selenium inhibition of tumorigenesis. Adv Exp Med Biol 1986; 206: 465-72.

32. Combs GF Jr. Selenium and cancer. In: Wang Z, ed. Biochemistry and Molecular Biology of Selenium. Beijing, China: Chinese Academy of Science, 1995.
33. Adlercreutz $\mathrm{H}$, Bannwart $\mathrm{C}$, Wahalasnm $\mathrm{K}$ et al. Inhibition of human aromatase by mammalian lignans and isoflavonoid phytoestrogens. J Steroid Biochem Mol Biol 1993; 44: 147- 53.

34. Wang C, Makela T, Hase T, Adlercreutz H, Kurzer MS. Lignans and flavonoids inhibit aromatase enzyme in human preadipocytes. J Steroid Biochem Mol Biol 1994; 50: 205-12.

35. Wei H, Wei L, Frenkel K, Bowen R, Barnes S. Inhibition of tumor promoter-induced hydrogen peroxide formation in vitro and in vivo by genistein. Nutr Cancer 1993; 20: 1-12.

36. Messina MJ. Legumes and soybeans: overview of their nutritional profiles and health effects. Am J Clin Nutr 1999; 70 (Suppl.): 439S-450S.

37. Singh SV, Hu X, Srivastava SK et al. Mechanism of inhibition of benzopyrene-induced forestomach cancer in mice by dietary curcumin. Carcinogenesis 1998; 19: 1357-60.

38. Pereira MA, Grubbs CJ, Barnes LH et al. Effects of the phytochemicals, curcumin and quercetin, upon azoxymethane- induced colon cancer and 7,12 dimethylbenzanthracene- induced mammary cancer in rats. Carcinogenesis 1996; 17: 1305-11.

39. Hong WK, Endicott J, Itri LM et al. 13-cis-retinoic acid in the treatment of oral leukoplakia. N Engl J Med 1986; 315: 1501-5.

40. Lippman SM, Kessler JF, Meyskens FL Jr. Retinoids as preventive ad therapeutic anticancer agents (Part 1). Cancer Treatment Rep 1987; 71: 391-405.

41. Sankaranarayanan R, Mathew B. Retinoids as cancerpreventive agents. In: Stewart BW, McGregor D, Kleihues P, eds. Principles of Chemoprevention. Lyon, France: IARC Scientific Publishers, 1996; 4760.

42. Omenn GS. Micronutrients (vitamins and minerals) as cancer-preventive agents. In: Stewart BW, McGregor D, Kleihues P, eds. Principles of Chemoprevention. Lyon, France: IARC Scientific Publishers, 1996; 3346.

43. Schwartz GG, Hulka BS. Is vitamin D deficiency a risk factor for prostate cancer? (Hypothesis). Anticancer Res 1990; 10:1307-11.

44. Freudenheim JL, Graham S, Marshall JR, Haughey BP, Cholewinski S, Wilkinson G. Folate intake and carcinogenesis of the colon and rectum. Int $\mathrm{J}$ Epidemiol 1991; 20: 368- 74

45. Giovannucci E, Stampfer MJ, Colditz GA et al. Folate, methionine, and alcohol intake and risk of colorectal adenoma.J Natl Cancer Inst 1993; 85: 875-84. 
Access full text article on other devices

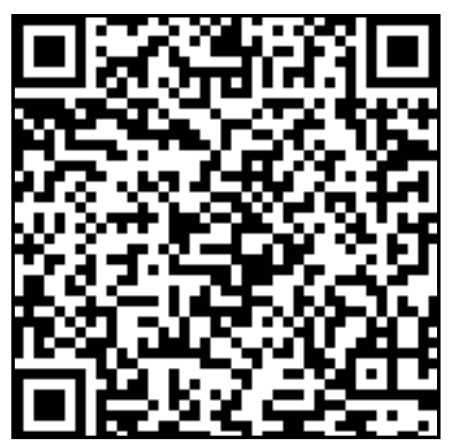

Access PDF of article on other devices

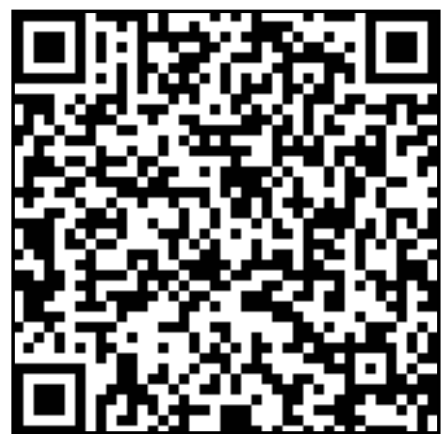

